\title{
Achieving the Physical Activity Guidelines during the Wintertime While Engaging in MyWinter and MyWinterHoliday Activity
}

\author{
M. Felicia Cavallini ${ }^{1, *}$, David J. Dyck ${ }^{2}$ \\ ${ }^{1}$ Limestone College, Gaffney, South Carolina, USA \\ ${ }^{2}$ University of Guelph, Guelph, Ontario, Canada \\ *Corresponding author: fcavallini@limestone.edu
}

Received July 31, 2019; Revised August 20, 2019; Accepted August 21, 2019

\begin{abstract}
Despite decades of research on the benefits of physical activity (PA) and exercise, many Americans and Canadians still do not engage in the recommended levels of PA. Only 15\% of Canadian adults obtain the recommended 150 minutes of moderate-to-vigorous physical activity (MVPA) per week according to the Canadian Health Measures Survey. The purpose of this study was to examine adults' physical barriers to PA and exercise to ultimately improve PA participation. In phase I, facilitated focus group discussions were conducted with 234 adults from 13 diverse groups in Guelph, Ontario, Canada regarding their physical barriers to PA and exercise. Among the physical barrier questions asked were: i) is winter weather a hindrance to engaging in PA?; ii) are you less likely to feel motivated to partake in PA in cold weather? Using the transcriptions from phase I, a survey was designed and administered to participants of the same community groups in phase II of the study to quantify feedback. Questionnaire responses were provided by 277 adults. Winter weather was the only significant physical barrier from the all respondents group, particularly among females. Recommendations for overcoming the barriers that contribute to low participation in PA in cold weather are discussed. To help incorporate a culture and environment of being active during the winter months, promotional and marketing strategies are identified through the introduction of MyWinter and MyWinterHoliday Activity graphics. Incorporating realistic, doable and even enjoyable daily indoor and outdoor PA strategies during winter are advocated.
\end{abstract}

Keywords: physical activity barriers, winter weather, intervention strategies, lifestyle physical activity, Canadian

Cite This Article: M. Felicia Cavallini, and David J. Dyck, "Achieving the Physical Activity Guidelines during the Wintertime While Engaging in MyWinter and MyWinterHoliday Activity." Journal of Physical Activity Research, vol. 4, no. 2 (2019): 118-125. doi: 10.12691/jpar-4-2-7.

\section{Introduction}

Physical inactivity increases the risk of all-cause mortality through obesity, cardiovascular disease, cancer, type II diabetes, increased levels of circulating low-density lipoprotein (LDL) cholesterol and triglycerides, high blood pressure, depression, osteoporosis and anxiety causing approximately 2 million deaths per year (World Health Day, 2007; https://www.who.int/mediacentre/news/releases/2007/pr1 1/en/). However, many Americans and Canadians remain physically inactive and do not engage in the recommended levels of PA. According to the U.S. Department of Health and Human Services [1] and the Canadian Society for Exercise Physiology (CSEP, 2012), adults should engage in at least 150 minutes of moderate to vigorous physical activity (MVPA) and at least 2 or more strengthening activities throughout the week. Only 22\% of Americans meet the guidelines for both moderate to vigorous PA (MVPA) and 2 days of muscle-strengthening activity per week [1]. Most Canadian adults (85\%) do not obtain the recommended PA and strength training each week $[2,3,4]$.

The Canadian Society of Exercise Physiology (https://www.csep.ca//view.asp?ccid=580) defines PA as any bodily movement that increases heart rate and breathing, and any movement produced by skeletal muscle that requires energy expenditure. Examples include walking, taking the stairs, gardening, housework and dancing. Moderate to vigorous PA is defined as 50 to $80 \%$ of an individual's maximal aerobic capacity. Exercise refers to the continuous, repetitive movements done with an intent to attain or maintain physical fitness such as running, lifting weights or taking a step bench, group fitness class. Keeping in mind MVPA is the weekly goal [1], there are still health benefits to any level of PA and reducing sedentary time [5].

\subsection{Physical Barriers to Physical Activity}

Environmental conditions such as wind, high humidity, precipitation and extreme cold can negatively impact PA 
participation $[6,7,8]$ as well as the amount of PA participation among all people [9]. Various studies indicate inclement weather serves as a PA barrier similarly to both men and women [10] while other research point to weather as a barrier to PA among women [11,12,13]. Since cold weather can be a physical barrier, this implies that more PA is accomplished in summer, autumn and spring [14,15,16]. McCormack et al. [17] revealed that walking for transportation (active transportation) was more probable in autumn, walking for recreation was more likely in the summer, autumn and spring, and moderate PA was greater in the summer. Seasonality, or the health behavior that either increases or decreases with the seasons or specific periods of the year, can affect PA involvement [16]. Also, the time of the year and length of the day can strongly influence PA levels year round [18]. Some research has shown that when PA engagement stops, this habit may lead to a permanent sedentary lifestyle, which ultimately can place individuals at risk for coronary heart disease and other risks associated with inactivity [19].

A large scale study in Scotland (7,202 males and 9,284 females) reported a 32\% higher involvement in PA with a duration of at least 20 minutes or more, three or more times a week during the peak summer time in July [19]. The frequency and duration of their PA during the winter period decreased by 23\%. Correspondingly, in two separate studies in Norway and Holland, total energy expenditure of both males and females decreased in winter compared to the summer $[19,20]$. In the United States, a similar report from the Behavioral Risk Factor Survey indicated a $15-20 \%$ increase in leisure-time PA during the summer and spring season with the highest energy expenditure during the summer as compared to PA levels during the winter months [15].

Merchant, Dehghan and Akhtar-Danesh [21] concluded that $\sim 65 \%$ of Canadians were inactive during the winter, compared to $\sim 50 \%$ during the summer. Moreover, caloric expenditure was $31 \%$ higher in the summer than the winter, as well as a $47 \%$ higher frequency of engaging in at least 15 minutes of PA in the summer. Similarly, leisure related PA was $86 \%$ higher in the summer than in the winter. PA rates were also higher in the autumn and spring, although not as high in the summer. Even PA lasting more than 15 minutes was $72 \%$ higher in the summer than winter. This furthers the point that winter is the most challenging season to stay physically active.

While environmental conditions, such as seasonal changes, have often been thought to influence the likelihood of engaging in PA, this is not without some controversy. A review of 19 journal articles that assessed the relationship between PA and environmental factors, found only a weak correlation between the two [22]. However, a more recent and extensive review of 37 journal articles [16] concluded that there was variation in PA levels due to seasonal changes. Moreover, poor to extreme weather was identified as a barrier to participation in PA [16]. These findings were further supported by Belanger et al. [23] who reported a decline in PA levels of adolescents in relation to seasonal changes. Furthermore, there is evidence that physical barriers are more prevalent in elderly adults, and in females [24].

\subsection{Research Question}

The literature indicates that seasonal changes affect one's likelihood to be physically active [7,25]. Our overarching research question, simply put, was "what are the most significant physical barriers to engaging in PA?" To this end, we generated a survey questionnaire based on feedback from focus groups, which attempted to identify the most significant physical barriers. Essentially, we attempted to answer "what are the physical barriers preventing the majority of Canadians from engaging in more PA?"

\subsection{Purpose of the Study}

Although numerous endeavors have been implemented to promote exercise and PA, there has been little change in PA levels among Canadian adults [26,27]. The focus of the current study was to determine the most significant physical (including weather) barriers to PA in a group of Canadian adults. The research design employed was a mixed methodology approach conducted in two phases. The first phase was qualitative, in which focus group discussions were conducted to gain an understanding of common barriers and awareness of peoples' perceptions of PA and exercise. This served to guide the formation of a quantitative survey, which was administered in phase II to identify the most common barriers to PA.

The purpose of this study was to i) examine adults' physical barriers to PA and exercise, ii) determine if any gender differences existed across all age groups, and iii) identify the most significant physical barriers. It was hypothesized that winter would be a significant physical barrier for both the males and the females.

\section{Methods}

\subsection{Participants}

Clearance was obtained from the University of Guelph Research Ethics Board. The first phase of the study concentrated on the phenomenological, qualitative approach to gathering data through facilitated focus group discussions. From December of 2014 to May of 2015, 1557 adults ages 18 years and older, representing 13 diverse groups from rural and urban communities in Southwestern Ontario, Canada were invited to participate in this study. Participants represented a diverse range of community groups including two rural area secondary schools, a rural Parks and Recreation Department, Lion's Club, a rural Mennonite church, a women's advocacy group called Zonta International of Guelph, Guelph YMCA/YWCA, Italian Canadian Club of Guelph, Men's Club of Guelph, Rotary Club of Guelph, University of Guelph students majoring in Hospitality, Food and Tourism Management, University of Guelph Choir, and Wyndham House whose main mission is to prevent, reduce, and end youth homelessness in Guelph.

A designated contact person from each of the 13 diverse focus groups received an e-mail with 3 sets of information attached to distribute to the members in their 
respective groups. The first was a letter of information prior to the focus group discussion, which included both the inclusion and exclusion criteria. Purposeful sampling was employed targeting specific, diverse focus groups that shared common interests and activities in which the members were then eligible to lend themselves to a facilitated group discussion. To participate in the study, participants had to be: (1) 18 years of age or older, (2) a resident of either the City of Guelph or the Counties of Wellington and Dufferin, and (3) a member of one of the community groups in the study. The exclusion criteria were any health conditions that precluded a participant from exercising. The selection of participants was non-random. Each contact person per focus group asked for volunteers who would be willing to express their opinions, beliefs and attitudes regarding physical activity and exercise in order to achieve depth of understanding. The second information document highlighted sample discussion questions, and the third document was the informed consent, which contained the purpose, procedures, and importance of the study, potential risks and discomforts, benefits to participation and assurance of confidentiality.

\subsection{Procedure}

\subsubsection{Phase I}

Focus group facilitated discussions were conducted with 234 people (15\% of the total potential sample of 1557) representing the various groups of participants previously identified. Ten of the thirteen groups included 6-12 participants and the other three were larger simply because of the type of group represented. Focus group interviews were held in a preferred meeting place for each group. Every effort was made to create a comfortable atmosphere in order to facilitate a relaxed discussion. Conversations were not recorded and each participant was reassured that the discussions would be kept confidential. Participants were urged to share their experiences and articulate their feelings regarding physical activity or exercise in this environment of minimum structure other than gently probing questions to allow thoughts to flow freely and allow for in-depth conversation.

At the beginning of each session, participants were asked to complete a short demographic questionnaire. The focus group discussions lasted approximately 30 to 60 minutes and participants were free to leave at any time. Guiding questions that centered around physical barriers included the following: Is the season of winter a barrier for you? Do you find being physically active during the winter months to be challenging? If so, why do you feel this way? If not, how do you stay active during the winter months? Does pain or injury prevent you from being physically active? Do you feel like you can be physically active in a safe environment? Are there opportunities or resources for you to be physically active at your worksite? Further probing questions followed and were dependent upon the participants' initial responses. Overall, the conversations were navigated to explore underlying factors for the overall lack of physical activity or exercise found in the Canadian adult population, and in particular, pertaining to cold/winter weather.

Focus group discussions were facilitated by the same trained, content expert. In addition, in order to insure consistency, 1-2 representatives from a group of 7 students were present at all focus groups for note taking and interpretation of the discussions. No self-identifying information was recorded, Upon completion of each focus group discussion, the students sent their typed notes to the group facilitator for thorough review. In an effort to understand the perspectives and interpret the experiences of the participants, the data were analyzed through a phenomenological approach. In trying to understand and provide meaning to the explanations of the experiences relating to physical barriers to PA and exercise from the focus group participants, the notes were meticulously and consistently reviewed for each focus group by one skilled facilitator multiple times in corroboration with the students to allow essential ideas to emerge. There was complete agreement of the interpretation of the notes between the group facilitator and note takers after each focus group. In addition, the trained content expert facilitator consulted with two outside content experts throughout the entire process. This was an exhaustive process, but these steps were taken in order to insure that the interpretation of the focus group feedback was never biased by one person's perception. With that in mind, it should be noted that the other content experts were not present at the focus groups. This was simply not feasible and might have been overwhelming for the participants. The aim was to identify the most recurring physical barrier themes emphasized by the participants. Among them, winter weather was a factor related to physical activity and exercise. "Winter weather is a problem," was then categorized under a separate heading and color-coded to arrange the comments/feedback reflecting this category, and included: "Psychologically, cold weather makes me want to stay indoors," "When I get home, all I want to do is stay indoors and keep warm," "I get the winter blahs when it's too cold for long periods of time", "I'm just not motivated to move when it's cold," "I hate the cold!”.

\subsubsection{Phase II}

From the feedback given in phase I of the study and using the themes that emerged from the focus group interviews, a research-generated survey was created to validate the findings of the initial focus group interviews. With this purpose in mind, common themes and trends that emerged on the physical barriers to physical activity and exercise from the focus group interviews were identified and analyzed by three content experts with backgrounds in physical education and exercise. These themes (agreed upon by all 3 experts) were then used to construct a series of descriptive statements related to physical barriers to PA to reflect the responses from the focus group interviews. The team of content specialists collaborated throughout the process in framing the descriptive statements with input of each member carefully considered while cooperatively working towards unanimous consensus.

Since phase I of the study was qualitative, it was imperative the research-generated survey accurately reflected the potential physical barriers identified in the focus groups. Because there was unanimous agreement among the note takers, the group facilitator and the content experts, all survey items reflected what was heard in the focus group discussions from phase I. There was no 
adding or modifying questions in the construction of the survey that did not reflect the responses of the participants nor was there any adjustments of the wording and format made in the survey in between each survey administration. This helped to ensure the reliability and validity of the survey in that only the remarks made regarding their barriers to PA were being measured and nothing else. The survey was designed to complete in approximately 10 minutes by having each person place a check near the descriptions that most closely aligned with their physical PA barriers. The responses from the survey data were consistent with the information conveyed from the focus groups.

Phase II of this study was cleared by the University of Guelph Research Ethics Board prior to distribution of surveys from July 15 to September 30, 2015 to 323 individuals in the same community groups where the focus group data were initially collected. Following another letter of invitation, informed consents from these participants were obtained. Survey administration was scheduled at a convenient time and location suitable for each group with the objective of obtaining as many participants as possible. Participation in the focus group discussions was not required for completion of the survey. Basic demographic information (age, gender, place of residence) was collected. Participants were asked to answer "yes" or "no" for each of the descriptive statements listed under the physical barrier section.

i) Which of the following, if any, do you consider to be YOUR "physical” barriers to physical activity and exercise?

ii) Winter weather is a factor for me when it comes to physical activity and exercise

iii) I'm concerned for my safety

iv) Pain and/or injury prevents me from being as physically active as I would like to be

v) I work in an environment where there are little or no employment resources to be physically active vi) My job demands and I'm too tired after work to exercise afterwards

vii) Other, please specify:

\subsection{Data Analysis}

Eighty-six percent (277/323) of the surveys distributed were completed providing valid survey data for further analyses. Data analysis for the physical barriers to PA section involved primarily descriptive statistics. Care was taken regarding the accuracy of the response recording; occasionally, participants did not respond to one or more barrier descriptors on the survey, particularly if the participant did not identify with any of the listed physical barriers. Participants' responses to the survey were organized in a spreadsheet (Microsoft Excel) according to gender and in the following age groups: 18-34, 35-64, and 65 and older. The total number of participants in each category (with respect to gender and age) was determined for each question. Descriptive statements from the physical barriers to PA survey required "Yes" or "No" answers and were recorded accordingly. Chi-square analysis and Fisher's exact test were used to test for significant relationships.

\section{Results}

Table 1 indicates the number and percentage of survey respondents according to age and gender. Of the 1,557 individuals initially invited to participate in the focus groups, we invited 323 participants to complete the surveys. Two hundred and seventy seven people completed the survey (61\% males, 39\% females) from either the 18-34, 35-64, or 65 and older group. This was a very high response rate $(86 \% ; 277 / 323)$ for the survey.

Table 1. The number and percentage of survey respondents according to age and gender

\begin{tabular}{|c|c|c|c|c|}
\hline & All ages & $18-34$ years & 35-64 years & $80(29 \%)$ \\
\hline Number of respondents & $277(100 \%)$ & $84(30 \%)$ & $45(27 \%)$ & $113(41 \%)$ \\
\hline Males & $170(61 \%)$ & $21(12 \%)$ & $104(61 \%)$ \\
\hline Females & $107(39 \%)$ & $63(59 \%)$ & $35(33 \%)$ & $9(8 \%)$ \\
\hline
\end{tabular}

Table 2. Male and female responses to survey questions related to the association of descriptive statements related to physical barriers to physical activity. Numbers represent the percentage of total respondents answering "Yes" to the question.

\begin{tabular}{|c|c|c|c|c|}
\hline Descriptive statements & All respondents & Ages 18-34 & Ages 35-64 & Ages 65 and older \\
\hline Sample size, $\mathrm{n}=$ & $\begin{array}{l}\text { Male, } 162-170 \\
\text { Female, } 105-107\end{array}$ & $\begin{array}{c}\text { Male, 19-21 } \\
\text { Female, 61-63 }\end{array}$ & $\begin{array}{l}\text { Male, } 40-45 \\
\text { Female, } 35\end{array}$ & $\begin{array}{l}\text { Male, 103-104 } \\
\text { Female, } 9\end{array}$ \\
\hline $\begin{array}{l}\text { *Winter weather is a factor for me when it comes } \\
\text { to physical activity and exercise }\end{array}$ & $\begin{array}{c}\text { Male } 40 \% \\
\text { Female } 60 \%\end{array}$ & $\begin{array}{c}\text { Male 38\% } \\
\text { Female 67\% }\end{array}$ & $\begin{array}{c}\text { Male } 36 \% \\
\text { Female } 49 \%\end{array}$ & $\begin{array}{c}\text { Male } 42 \% \\
\text { Female 56\% }\end{array}$ \\
\hline I'm concerned for my safety & $\begin{array}{c}\text { Male 9\% } \\
\text { Female 7\% }\end{array}$ & $\begin{array}{c}\text { Male 5\% } \\
\text { Female 8\% }\end{array}$ & $\begin{array}{c}\text { Male 7\% } \\
\text { Female 3\% }\end{array}$ & $\begin{array}{c}\text { Male } 12 \% \\
\text { Female } 11 \%\end{array}$ \\
\hline $\begin{array}{l}\text { Pain and/or injury prevents me from being as } \\
\text { physically active as I would like to be }\end{array}$ & $\begin{array}{c}\text { Male 37\% } \\
\text { Female 25\% }\end{array}$ & $\begin{array}{c}\text { Male 29\% } \\
\text { Female 22\% }\end{array}$ & $\begin{array}{c}\text { Male 29\% } \\
\text { Female 23\% }\end{array}$ & $\begin{array}{c}\text { Male } 42 \% \\
\text { Female 56\% }\end{array}$ \\
\hline $\begin{array}{l}\text { I work in an environment where there are little or } \\
\text { no employment resources to be physically active }\end{array}$ & $\begin{array}{c}\text { Male } 9 \% \\
\text { Female } 14 \%\end{array}$ & $\begin{array}{c}\text { Male } 10 \% \\
\text { Female } 11 \%\end{array}$ & $\begin{array}{c}\text { Male } 18 \% \\
\text { Female } 23 \%\end{array}$ & $\begin{array}{c}\text { Male 6\% } \\
\text { Female 0\% }\end{array}$ \\
\hline $\begin{array}{l}\text { My job demands are high and I'm too tired after } \\
\text { work to exercise }\end{array}$ & $\begin{array}{c}\text { Male } 14 \% \\
\text { Female } 32 \%\end{array}$ & $\begin{array}{c}\text { Male 38\% } \\
\text { Female 33\% }\end{array}$ & $\begin{array}{c}\text { Male } 27 \% \\
\text { Female } 31 \%\end{array}$ & $\begin{array}{c}\text { Male } 4 \% \\
\text { Female } 22 \%\end{array}$ \\
\hline
\end{tabular}

*There was no significant relationship between responses to cold weather as a barrier, and any of the other barriers indicated in Table 2 . 


\subsection{Physical Barriers}

The physical (environmental) barrier of "winter weather," was especially supported by the females with the bulk of all the female participants (60\%) and the 18-34 year olds (67\%) acknowledging, "Winter weather is a factor for me when it comes to physical activity and exercise" followed by a weaker, yet noteworthy indication from the 35-64 (49\%) and 65 and older (56\%) age groups. Similarly, $56 \%$ of the females in the 65 and up group indicated, "Pain and/or injury prevents me from being as physically active as I would like to be.” Safety concerns, lack of employment resources to be physically active (work environment) and job demands plus feeling too fatigued after work were not indicated as prevalent barriers by either gender.

\section{Discussion}

When viewing the cumulative responses of all respondents in Table 2, participants who identified winter as a barrier with a $50 \%$ or greater response rate, were all, interestingly, females. This was not consistent with our hypothesis. In fact, winter was the only significant physical barrier indicated by the females in this study. The highest response rate came from the females in the 18-34 age group (67\% indicating "Yes"). Nonetheless, all participants including the males still identified cold weather as being the most significant physical barrier, being at least equal to or greater than physical injuries. In retrospect, in addition to dealing with the cold weather barrier, we speculate that the younger females may feel that the decision to engage in PA or exercise directly conflicts with other duties of their life, which take priority and require their attention, including college, marriage, children, etc.

Consistent with previous research findings, winter (cold weather) presents a barrier for many people, and some studies point to the tendency for PA to decrease in the colder months $[6,16,28,29]$. Colder weather is also associated with a decreased usage of trails and parks [30], as well as participation in outdoor physical activities [16]. In contrast to winter, moderate to vigorous physical activity including walking for recreational and transportation purposes are more likely and expected in the summer, fall and spring [17]. Therefore, developing and cultivating an environment, which encourages people to engage in PA during the winter, is extremely important. Promoting images of people partaking in PA during the winter (Figure 1, MyWinter Activity and Figure 2, MyWinterHoliday Activity) can help psychologically engrain an accepted physically active mindset during the cold winter months to help reinforce a message that PA doesn't have to stop or even decline when it's cold.

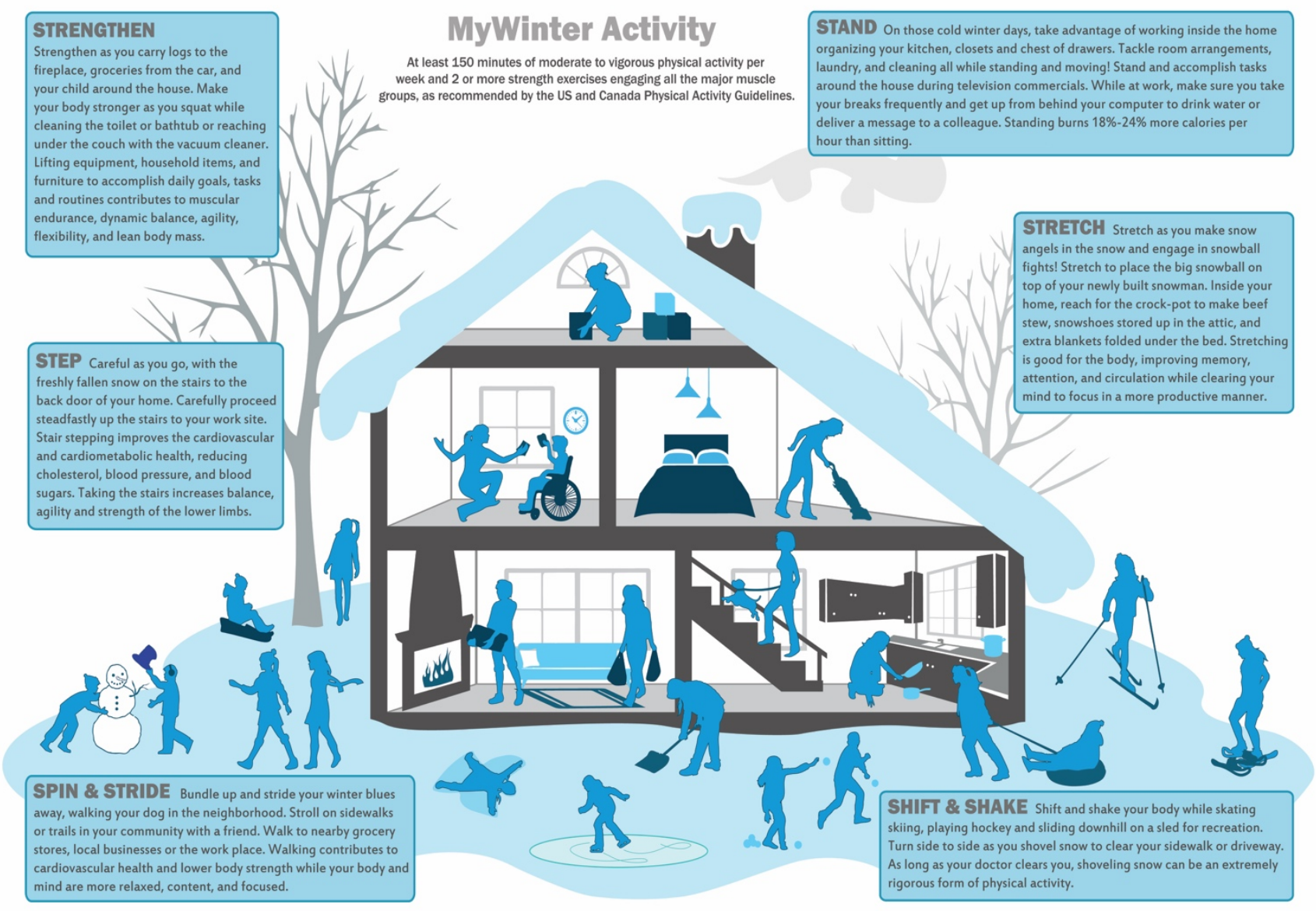

() 2019 MyWinter Activity, Dr. M. Felicia Cavallini. All Rights Reserved.

Figure 1. MyWinter Activity 


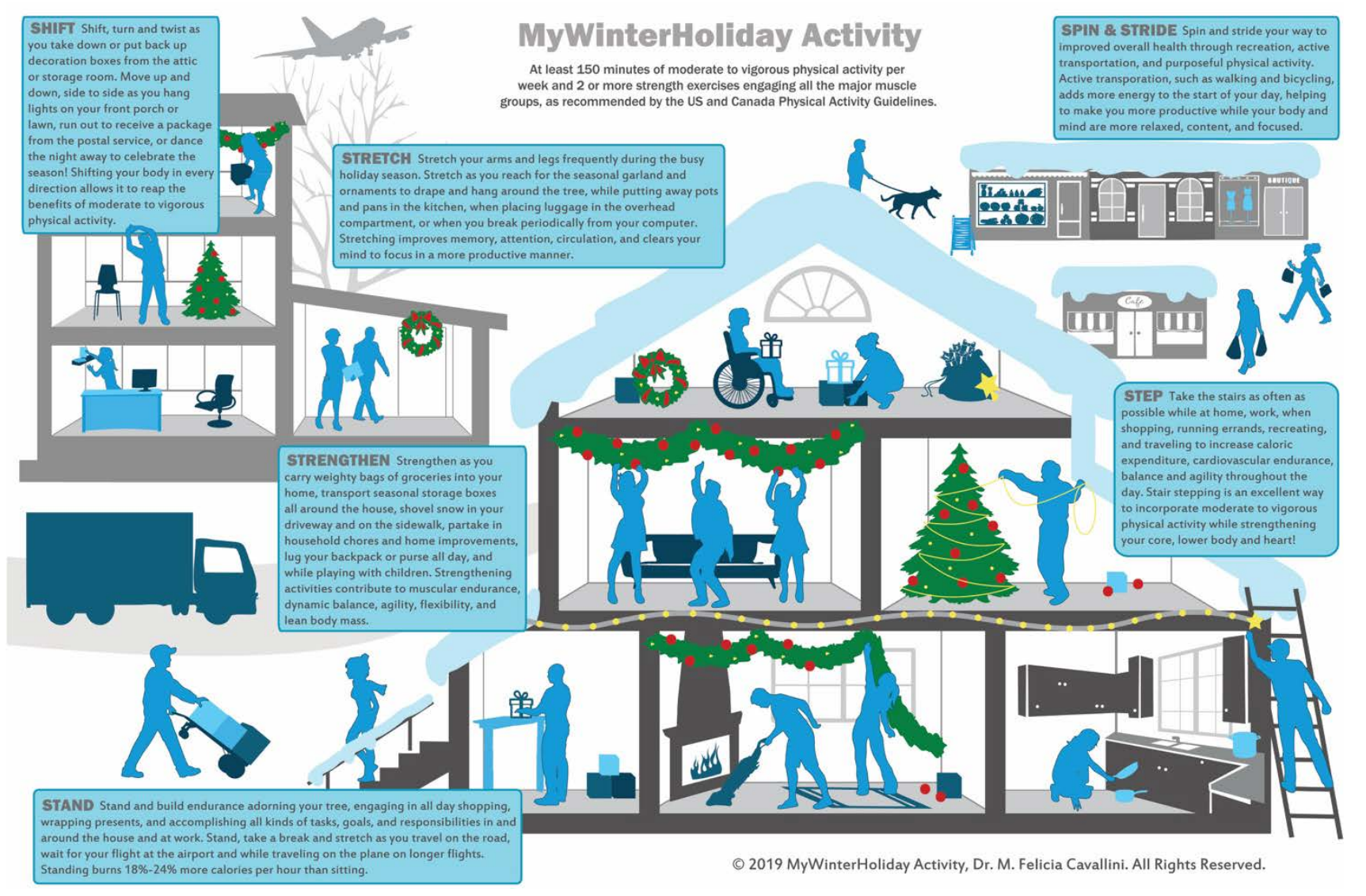

Figure 2. MyWinterHoliday Activity

Many of the participants in Phase I of this study did mention that they disliked cold weather, and that it set the mood to not want to do anything outside. There is a clear decrease in PA during the winter. Accordingly, interventions should be implemented to encourage people to participate in PA during the winter by increasing awareness and giving more access to indoor facilities. Perhaps psychologically embracing winter weather and continuing to keep an active lifestyle in and around the home can help maintain the recommended PA guidelines of 150 minutes of moderate to vigorous PA per week. Instead of fighting the weather, people need to embrace the change and let nature inspire the shift of PA patterns in a more meaningful way while household responsibilities, work assignments and personal goals and objectives are fulfilled. Going outdoors may not be as appealing but viable alternatives can be achieved at home. For those attracted to outdoor PA during the winter, bob sledding, snow shoeing, ice skating or cross-country skiing are all popular, vigorous activities. Proper attention to clothing, including effective layering of warm outerwear may make it more pleasant to go outside and engage in active transportation or recreational walking. For those who prefer to socialize while being physically active, walking or participating in recreational activities in groups should be encouraged, and even promoted with graphics promoting images of crowds of people exuding PA in every setting.

Increasing PA over the winter season can also help minimize and control weight gain that contributes to obesity. Given the decrease levels of physical activity during the winter and the accumulation of increased caloric intake [31], over the years, the level of obesity may rise [32]. This is another reason to embrace PA year round, particularly in cold weather. Winter can be the perfect time of the year to reflect, organize and prepare for the future. Turn spring cleaning into winter cleaning. Tackle those boxes tucked away you've been meaning to go through forever. Organize your clothes closet, kitchen pantry and utility room. Engage in home improvements. In the house, rearrange furniture and renovate rooms. Embrace the physical activities that go along with winter-snow ball fights, sledding, snow shoeing, ice skating, shoveling snow or cross country skiing. Cultivate and nurture your hobbies during the winter that keep you mentally positive and potentially active around the house. Use your body weight and natural surroundings inside the home to incorporate MVPA such as taking the stairs as often as possible while doing laundry, pacing the house while talking on the phone, and squatting or short stride lunging instead of bending over to grab the pots and pans needed for dinner. Engage in all kinds of functional lifestyle movements with a weighty object from the house such as picking up and playing with the baby, carrying heavy grocery bags into the kitchen or storing winter boxes in the attic. Welcome the holiday season with open arms. Shopping, dancing, celebrating with friends and decorating all require physical energy!

The few studies conducted in the areas of PA preferences, point to the tendency for a preference for day-to-day lifestyle PA over exercise [33,34,35]. If we recognize that only $15 \%$ of Canadians are meeting the recommended guidelines for PA to date [2], then it stands that acquiring the health benefits through unstructured or lifestyle PA has not been proportionally taught and promoted to parallel peoples' preferences for meeting the PA guidelines. It may be that the perception of exercise 
hinders people from believing that they can accomplish PA without having to go to the gym or performing more traditional exercise. This, combined with overcoming the physical barrier of cold weather, may make meaningful participation in PA feel unachievable and insurmountable. Efforts should be made to dynamically increase PA by making specific choices during the course of the day at both work and home, as well as to incorporate greater amounts of active transportation (walking) where-ever possible, knowing that this is where much of the decisionmaking to increase PA lies. Completing tasks at home or performing useful work is often part of lifestyle PA and as a result, people may be more inclined to perform these kinds of PA rather than explicit prescribed exercise, especially during the winter. Cold weather is a great opportunity to embrace household tasks indoors or even outdoors. Be observant of your PA throughout the day and don't dismiss any opportunity to incorporate PA. Buying groceries and carrying heavy bags, shoveling and clearing snow, and taking the stairs all have excellent health benefits. Decorating the tree, carrying boxes down from the attic and taking packages to the post office all have PA merits. While indoors, make the progress of accomplishing tasks a little more difficult by going up and down the stairs at home or at work more often. This will help keep the PA level in the moderate to vigorous zone during the course of the day. In addition, adjust the environment according to the weather. Instead of walking outside, walk indoors at the mall or in a large commercial building [36,37].

In conclusion, the literature, as well as the current study, strongly supports the idea that being physically active during cold weather can be challenging and a significant barrier for many people. Examining intervention strategies, educating, promoting and marketing ways in which people can maintain their PA level in frigid temperatures is necessary to overcome this physical barrier in order to attain the recommended guidelines for PA. Developing an approach and outlook that embraces winter for a healthier body through meaningful indoor and outdoor PA is essential to a continued MVPA lifestyle in colder climates. Peoples' preferences for lifestyle PA can achieve the PA guidelines during the wintertime with a thoughtfully considered everyday life existence.

\section{Acknowledgements}

Dr. Cavallini was the recipient of a US Fulbright Scholarship in 2014-2015 during which time this study was conducted.

\section{Statement of Competing Interests}

The authors have no competing interests.

\section{References}

[1] Services, USDoHaH. U.S. Department of Health and Human Services, Center for Disease Control and Prevention 2018; Available from:

https://www.cdc.gov/physicalactivity/basics/measuring/heartrate.h tm.
[2] Colley, RC, Garriguet D, Janssen I, et al. Physical activity of Canadian adults: accelerometer results from the 2007 to 2009 Canadian Health Measures Survey. Health Reports 2011; 22(1): 7-14.

[3] Shields, M, Tremblay MS, Laviolette M, et al. Fitness of Canadian adults: results from the 2007-2009 Canadian Health Measures Survey. Health Reports 2010; 21(1): 21-35.

[4] Colley, RC, Garriguet D, Janssen I, et al. Physical activity of Canadian adults: Accelerometer results from the 2007 to 2009 Canadian Health Measures Survey. Health Reports 2011; 22(1).

[5] Healy, GN, Winkler EAH, Eakin EG, et al. A Cluster RCT to Reduce Workers' Sitting Time: Impact on Cardiometabolic Biomarkers. Medicine and Science in Sports and Exercise 2017; 49(10): 2032-2039.

[6] Chan, CB, Ryan DA, and Tudor-Locke C. Relationship between objective measures of physical activity and weather: a longitudinal study. International Journal of Behavioral Nutrition and Physical Activity 2006; 3: 21.

[7] Merrill, RM, Shields EC, White GL, Jr., et al. Climate conditions and physical activity in the United States. Am J Health Behav 2005; 29(4): 371-81.

[8] Togo, F, Watanabe E, Park H, et al. Meteorology and the physical activity of the elderly: the Nakanojo Study. International Journal of Biometeorology 2005; 50(2): 83-89.

[9] Berkey, CS, Rockett HRH, Gillman MW, et al. One-year changes in activity and in inactivity among 10-to 15-year-old boys and girls: Relationship to change in body mass index. Pediatrics 2003; 111(4): 836-843.

[10] Humpel, N, Owen N, Iverson D, et al. Perceived environment attributes, residential location, and walking for particular purposes. American Journal of Preventive Medicine 2004; 26(2): 119-125.

[11] Currie, JL and Develin E. Stroll your way to well-being: a survey of the perceived benefits, barriers, community support, and stigma associated with pram walking groups designed for new mothers, Sydney, Australia. Health Care Women Int 2002; 23(8): 882-93.

[12] Fahrenwald, NL and Walker SN. Application of the transtheoretical model of behavior change to the physical activity behavior of WIC mothers. Public Health Nursing 2003; 20(4): 307-317.

[13] Sanderson, B, Littleton MA, and Pulley LV. Environmental, policy, and cultural factors related to physical activity among rural, African American women. Women \& Health 2002; 36(2): 75-90.

[14] Merchant, AT, Dehghan M, and Akhtar-Danesh N. Seasonal variation in leisure-time physical activity among Canadians. Canadian Journal of Public Health-Revue Canadienne De Sante Publique 2007; 98(3): 203-208.

[15] Pivarnik, JM, Reeves MJ, and Rafferty AP. Seasonal variation in adult leisure-time physical activity. Medicine and Science in Sports and Exercise 2003; 35(6): 1004-1008.

[16] Tucker, P and Gilliland J. The effect of season and weather on physical activity: a systematic review. Public Health 2007; 121(12): 909-22.

[17] McCormack, GR, Friedenreich C, Shiell A, et al. Sex- and age-specific seasonal variations in physical activity among adults. Journal of Epidemiology and Community Health 2010; 64(11).

[18] Plasqui, G and Westerterp KR. Seasonal variation in total energy expenditure and physical activity in Dutch young adults. Obesity Research 2004; 12(4): 688-694.

[19] Uitenbroek, DG. Seasonal-Variation in Leisure-Time PhysicalActivity. Medicine and Science in Sports and Exercise 1993; 25(6): 755-760.

[20] Graff-Iversen, S, Anderssen SA, Holme IM, et al. An adapted version of the long International Physical Activity Questionnaire (IPAQ-L): Construct validity in a low-income, multiethnic population study from Oslo, Norway. International Journal of Behavioral Nutrition and Physical Activity 2007;4.

[21] Merchant, AT, Dehghan M, Behnke-Cook D, et al. Diet, physical activity, and adiposity in children in poor and rich neighbourhoods: a cross-sectional comparison. Nutrition Journal 2007; 6 .

[22] Humpel, N, Owen N, and Leslie E. Environmental factors associated with adults' participation in physical activity: a review. American Journal of Preventive Medicine 2002;22(3): 188-99.

[23] Belanger, M, Gray-Donald K, O'Loughlin J, et al. Influence of weather conditions and season on physical activity in adolescents. Annals of Epidemiology 2009; 19(3): 180-6.

[24] Schutzer, KA and Graves BS. Barriers and motivations to exercise in older adults. Preventive Medicine 2004; 39(5): 1056-61. 
[25] Tu, WZ, Stump TE, Damush TM, et al. The effects of health and environment on exercise-class participation in older, urban women. Journal of Aging and Physical Activity 2004; 12(4): 480-496.

[26] Shields, M, Tremblay MS, Laviolette M, et al. Fitness of Canadian adults: Results from the 2007-2009 Canadian Health Measures Survey. Health Reports 2010; 21(1).

[27] Warburton, DE, Charlesworth S, Ivey A, et al. A systematic review of the evidence for Canada's Physical Activity Guidelines for Adults. International Journal of Behavioral Nutrition and Physical Activity 2010; 7: 39.

[28] Duncan, JS, Hopkins WG, Schofield G, et al. Effects of weather on pedometer-determined physical activity in children. Medicine and Science in Sports and Exercise 2008; 40(8): 1432-8.

[29] Hamilton, SL, Clemes SA, and Griffiths PL. UK adults exhibit higher step counts in summer compared to winter months. Annals of Human Biology 2008; 35(2): 154-69.

[30] Wolff, D and Fitzhugh EC. The relationships between weather-related factors and daily outdoor physical activity counts on an urban greenway. International Journal of Environmental Research and Public Health 2011; 8(2): 579-89.

[31] Capita, R and Alonso-Calleja C. Differences in reported winter and summer dietary intakes in young adults in Spain. International Journal of Food Sciences and Nutrition 2005; 56(6): 431-443.
[32] Visscher, TLS and Seidell JC. Time trends (1993-1997) and seasonal variation in body mass index and waist circumference in the Netherlands. International Journal of Obesity 2004; 28(10): 1309-1316.

[33] Burton, NW, Khan A, and Brown WJ. How, where and with whom? Physical activity context preferences of three adult groups at risk of inactivity. British Journal of Sports Medicine 2012; 46(16): 1125-31.

[34] Cavallini, MF, Kolen AM, Sui X, et al. Introducing MyHouse Activity and MyWork Activity: A Paradigm Shift towards Lifestyle Physical Activity Supported by Evidence from a Focus Group Study Journal of Physical Activity Research 2017; 2(1): 61-67.

[35] Salmon, J, Owen N, Crawford D, et al. Physical activity and sedentary behavior: a population-based study of barriers, enjoyment, and preference. Health Psychology 2003; 22(2): 178-88.

[36] Choi, BCK, Pak AWP, Choi JCL, et al. Achieving the daily step goal of 10,000 steps: The experience of a Canadian family attached to pedometers. Clinical and Investigative Medicine 2007; 30(3): E108-E113.

[37] Culos-Reed, SN, Stephenson L, Doyle-Baker PK, et al. Mail walking as a physical activity option: Results of a pilot project. Canadian Journal on Aging-Revue Canadienne Du Vieillissement 2008; 27(1): 81-87.

C The Author(s) 2019. This article is an open access article distributed under the terms and conditions of the Creative Commons Attribution (CC BY) license (http://creativecommons.org/licenses/by/4.0/). 